\title{
Measuring Cognitive and Affective Performance in a Statistics Course that uses Online Computer Statistics Modules
}

\author{
Barry Mauldin, Teri Reed Rhoads \\ University of Oklahoma
}

\begin{abstract}
The advancement of educational technology has stimulated new ways to present course content. The goal of this research was to study the effect that computerized statistics modules (introductory platforms for statistics principles) have on students in an engineering statistics course. Effect was measured on two levels: cognitive and affective. Students from the engineering statistics course at the University of Oklahoma were evaluated. Cognitive performance was measured via grades earned on homework, tests, and projects. Affective performance was measured via a survey of their attitudes toward this statistics course and the topic of statistics in general. The study compares results from a semester that did not use computer modules and a semester that did use computer modules. There was found to be no statistical difference in cognitive performance between the two semesters. Similarly, no statistical difference in affective performance was discovered.
\end{abstract}

\section{Introduction}

The advancement of educational technology has stimulated new ways to present course content. Multimedia usage varies over a broad spectrum. It can include e-mail communication, on-line class notes, video lectures, animated instructions and simulated demonstrations. There are efforts by several engineering instructors to use the computer and Internet as a means to introduce topics or facilitate learning. Implementation of these multimedia tools has the potential to improve student performance.

One such multimedia tool is a computerized statistic module. These modules are animated tutorials that demonstrate some course topic. The modules present formal text definitions supplemented with working examples. For instance, the module could explain the concept of statistical mean and give the accompanying equation. Then the module could demonstrate how to calculate the mean. The modules are accessed via the course web site. The module can be viewed online or downloaded and viewed inside any typical web browser.

The goal was to study what impact the computerized statistics modules have on students in an 
engineering statistics course. Effect was considered on two levels: cognitive and affective. Cognitive level is an indicator of the student's mental understanding of the statistical material. This level is based on the student's ability to grasp the concepts and apply statistics successfully toward their assignments and projects. The affective level is a measure of the student's attitude toward engineering statistics. This level is meant to gauge the student's comfort with the material and his or her perceived relevance of statistics toward his or her own needs.

\section{Literature Review}

A literature search investigated previous endeavors that concerned integrating multimedia with academic course instruction. Particular emphasis was made on looking at engineering and other such technical courses. Foremost, the integration of multimedia with course instruction must enhance the learning experience. Traditional media items, such as overhead transparencies, 35mm slides, or videotape, no longer define multimedia. Multimedia now embraces modern applications such as computer tools, and the Internet. Hailey ${ }^{7}$ found there to be no statistical relevant difference in learning when the material was presented via traditional or digital multimedia. Azemi ${ }^{1}$ said that computer based instruction cannot replace lectures, but they can enhance them. Hawley and Crynes ${ }^{8}$ concur that multimedia technology has great potential to improve curriculum delivery. Taylor and Growler ${ }^{16}$ advise that information technology should not replace instructor-peer interaction, but enhance the relationship. Because of this, there is a great desire to find ways to utilize multimedia tools within course instruction.

The challenge is finding a good method to enhance the learning. Computer multimedia provides a lot of flexibility. This includes numerous tools, such as graphics, animation, video, audio, or some combination. It also includes the manner in which the media is delivered. Computer modules may also help students move into a higher level of thinking. These higher levels, according to Bloom's Taxonomy ${ }^{4}$, include analysis, synthesis, and evaluation. Rhoads, Zimmer, Lewis, and Hubele ${ }^{13}$ have attempted to move students in their statistics classes into these higher levels. They used computers in a laboratory setting for in-class exercises. Online multimedia has a significant advantage because students can view the content in a self-paced and asynchronous fashion ${ }^{17}$. Selfpacing has potential for significantly enhancing student's learning and retention of presented material as well as stimulating interest ${ }^{9}$. With online multimedia, introductory concepts and topics can be moved out of class time. According to Toogood, et al. ${ }^{17}$ most learning is done face-to-face. Thus, moving the passive aspect of teaching out of the classroom allows for the instructor to use the class meeting time for addressing individual problems and lead interactive exercises ${ }^{6}$. Additionally, the instructor can stay informed of student's strengths and weaknesses based on the multi-media's automatic feedback capability. Feedback gives the instructor the opportunity to customize the in-class instruction to the particular needs of the class ${ }^{9}$. Azemi ${ }^{1}$ stated that a requirement for multimedia courseware was to have a quiz section at the end of each lesson. The quiz provides instructors information about student understanding. The quiz also offers students an aide for material retention.

Module construction is very important to pedagogical effectiveness. For example, modules 
developed for topics in a basic physics class consisted of definition, example, review questions, and quiz ${ }^{9}$. Students received feedback automatically on their quiz performance. The quiz results were also sent to the instructor. Eighty percent of the students supported the value of these interactive learning modules. McCartney, et al. ${ }^{10}$ at the University of Connecticut wanted to integrate his Digital Design class with multimedia based content delivery. Students used online material to become familiar with theory. The instructor strove to mimic the laboratory support electronically. The multimedia also allowed for material to be flexible. That is, students could view the material at anytime and the material was hyper-linked in such a fashion as to point students to supplemental material. Again, the modules contained self -test questions to query students about the material, thus giving the instructor the ability to tailor a lecture to student needs.

This research also took advantage of the attitudinal aspect of course reception. Roiter and Petocz ${ }^{14}$ believe student anxiety and the affective domain should be considered when designing a statistics course. Rhoads and Hubele ${ }^{12}$ studied the effects that student attitude has upon student performance in a course. They sought to create an appreciation of their engineering statistics course by improving the student attitudes about the subject. They found research that suggests positive attitudes could be linked to higher concept retention and course performance ${ }^{2,3}$. They designed their engineering statistics course to use computer activities, as well as hands on assignments that utilized realistic engineering data. They found that students who own a computer, students who have previous statistics exposure and males have a more positive attitude in the beginning of the course. They also found engineering students who view statistics with relevance possess a more positive attitude. And, in regard to grades received, the students who earned the higher grades have a more positive attitude toward the course, both before and afterwards.

\section{Hypothesis}

Several hypotheses were addressed in this research so to examine the cognitive and attitudinal effects that computerized modules had on students in an engineering statistics course. These hypotheses were evaluated in accordance to the results of the Survey of Attitudes Toward Statistics ${ }^{15}$ (SATS) and performance on course assignments and projects.

The first hypothesis addressed whether there was a significant positive difference in academic performance between the semester without computerized modules and the semester with computerized modules. Such a positive change would lend credibility to the computerized modules. The modules were designed to reduce the introduction phase of material in the classroom. It was hoped that course topics could be covered more in depth. More importantly, it was hoped that by exposing students to course material prior to in-class instruction, the students would feel more comfortable with the material, and, in turn, be more receptive to the content.

Another hypothesis explored if there was a significant positive difference in attitude toward statistics between the semester without computerized modules and the semester with computerized modules. Again, it was hoped that the computerized modules made introduction of course material in this manner more agreeable. Should students be more understanding of the course content, it 
seems perhaps that this understanding may correlate with a better appreciation for the course.

An additional hypothesis was to see if there was a significant improvement in student attitude toward statistics from the beginning of the semester to the end of the semester. This analysis goes for both semesters in the study. The professor utilized strictly conventional teaching methods during the semester without statistics modules. It was hoped to determine if a student's attitude toward the course improved upon completion of the course. Perhaps an understanding of the material shapes attitude. More importantly, a positive improvement in attitude indicates a better grasp of the course content. The semester with statistics modules used traditional teaching methods supplemented with the computerized modules. Perhaps their presence could contribute to attitude improvement.

\section{Subjects}

The subjects used in this research were college students enrolled in the engineering statistics course (ENGR-3293) at the University of Oklahoma during the Spring 2000 and Fall 2000 semesters. Participation in the study was voluntary for the students. If a student decided to participate, he or she signed a consent form. There were 41 student subjects in the spring semester and 40 student subjects in the fall semester who completed both the pre and post semester surveys and consented to participate in the study.

The Institutional Review Board approved this research. Thus, the project was permitted under the regulations of the University of Oklahoma - Norman Campus Policies and Procedures for the Protection of Human Subjects in Research Activities. A consent form was made available to all students enrolled in the engineering statistics course for both the Spring 2000 and Fall 2000 semesters. The consent form was designed in accordance to the requirements of the Institutional Review Board. The form was necessary due to the fact that human subjects were being used.

\section{Task}

Students participating in the study completed all required assignments, tests, projects, computerized statistic modules, and attitude surveys. Students from the ENGR3293 engineering statistics course at the University of Oklahoma were evaluated over two semesters: Spring 2000 and Fall 2000. Course schedules were similar for the spring and fall courses (Table 1). The fall semester, however, included computerized statistics modules. Students were assigned to view these modules before a specified due date. The students also had to complete an associated quiz and survey with each module. The purpose of the module was to introduce students to particular statistic topics before the concerned topic was discussed in the classroom. 
Table 1: Course Schedule for Spring and Fall 2000

\begin{tabular}{|c|c|c|c|}
\hline Wk. & Spring 2000 Topics & Fall 2000 Topics & $\begin{array}{l}\text { Computerized } \\
\text { Modules }\end{array}$ \\
\hline 1 & $\begin{array}{c}\text { Pre-Survey } \\
\text { Descriptive Statistics }\end{array}$ & $\begin{array}{c}\text { Pre-Survey } \\
\text { Descriptive Statistics }\end{array}$ & $\begin{array}{c}\text { Descriptive } \\
\text { Statistics }\end{array}$ \\
\hline 2 & Discrete random variables & $\begin{array}{l}\text { Planning and reporting an } \\
\text { engineering statistical study } \\
\text { Project \#1 assigned }\end{array}$ & $\begin{array}{l}\text { Sample } \\
\text { Spaces }\end{array}$ \\
\hline 3 & $\begin{array}{c}\text { Goodness-of-fit testing } \\
\text { Continuous random variables and } \\
\text { probability distributions }\end{array}$ & $\begin{array}{l}\text { Discrete random variables and } \\
\text { probability distributions }\end{array}$ & \\
\hline 4 & $\begin{array}{c}\text { Continuous Uniform distribution } \\
\text { Quiz No. 1 }\end{array}$ & $\begin{array}{l}\text { Goodness-of-fit testing } \\
\text { Project \#1 Due }\end{array}$ & \\
\hline 5 & $\begin{array}{l}\text { Planning and reporting an } \\
\text { engineering statistical study } \\
\text { Midterm Project Assigned }\end{array}$ & $\begin{array}{c}\text { Continuous random variables and } \\
\text { probability distributions }\end{array}$ & \\
\hline 6 & $\begin{array}{l}\text { Chebychev's inequality } \\
\text { Central Limit Theorem } \\
\text { Confidence Intervals }\end{array}$ & Exam No. 1 & \\
\hline 7 & $\begin{array}{c}\text { Counting Methods } \\
\text { Probability } \\
\text { Midterm Project Plan } \\
\text { Quiz No. 2 }\end{array}$ & Midterm Project assigned & \\
\hline 8 & $\begin{array}{c}\text { Hypothesis Testing } \\
\text { Midterm Project Due }\end{array}$ & $\begin{array}{l}\text { Chebychev's inequality } \\
\text { Central Limit Theorem } \\
\text { Confidence Intervals }\end{array}$ & $\begin{array}{l}\text { Central Limit } \\
\text { Theorem }\end{array}$ \\
\hline 9 & & $\begin{array}{c}\text { Midterm Project Plan } \\
\text { Counting Methods } \\
\text { Probability } \\
\text { Hypothesis Testing } \\
\end{array}$ & Probability \\
\hline 10 & $\begin{array}{c}\text { Two Sample Statistical Inference } \\
\text { Quiz No. } 3\end{array}$ & $\begin{array}{l}\text { Two Sample Hypothesis } \\
\text { Statistical Inference }\end{array}$ & $\begin{array}{l}\text { Two-Sample } \\
\text { Hypothesis } \\
\text { Testing }\end{array}$ \\
\hline 11 & Final Project Assigned & $\begin{array}{c}\text { Midterm Project Due } \\
\text { Exam No. } 2 \\
\text { Final Project Assigned }\end{array}$ & \\
\hline 12 & $\begin{array}{l}\text { Joint probability distributions } \\
\text { Covariance and correlation }\end{array}$ & $\begin{array}{l}\text { Joint probability distributions } \\
\text { Covariance and correlation }\end{array}$ & \\
\hline 13 & $\begin{array}{l}\text { Regression } \\
\text { Quiz No. } 4 \\
\end{array}$ & Regression & \\
\hline 14 & Regression & & \\
\hline
\end{tabular}




\begin{tabular}{|c|c|c|c|}
\hline 15 & $\begin{array}{c}\text { Linear combinations of random } \\
\text { variables }\end{array}$ & $\begin{array}{c}\text { Linear combinations of random } \\
\text { variables }\end{array}$ & \\
& $\begin{array}{c}\text { Functions of random variables } \\
\text { Moment Generating Functions }\end{array}$ & $\begin{array}{c}\text { Functions of random variables } \\
\text { Moment Generating Functions } \\
\text { Exam No. 3 }\end{array}$ & \\
\hline 16 & Final Project - Poster Session & $\begin{array}{c}\text { Final Project - Poster Session } \\
\text { Post Survey }\end{array}$ & \\
\hline
\end{tabular}

Cognitive performance was measured via grades earned on homework assignments, tests, and projects. In particular, homework assignments relating to the module topics were examined to see if there was any change in understanding of these concepts. Mid-term and final projects were compared. These projects were similar assignments for both semesters; therefore these projects were good indicators of possible cognitive improvements. There were some differences between the two semesters. These included the number of exams ( 5 in the Spring semester and 3 in the Fall semester) and the number of projects ( 2 in the Spring semester and 3 in the Fall semester). An additional difference was the course websites used. The spring semester's website used conventional methods of course delivery (links, graphics, etc.). The fall semester's website used a pre-designed template provided by Blackboard corporation. The Blackboard website allowed for online collection of quizzes and surveys associated with each module.

Affective performance was measured via a survey of attitudes toward this statistics course and the topic of statistics in general. The Survey of Attitudes Toward Statistics (SATS) developed by Candace Schau ${ }^{15}$, from the University of New Mexico, was used. Students from both the spring and fall semester were surveyed with the same instrument. These surveys aided the present research in determining the ability of the computer statistics modules to improve student attitudes. There was a difference in administration methods of the surveys between the two semesters. The spring semester used traditional paper surveys that the students filled out by hand. The fall semester provided an electronic method for survey collection. Students accessed the surveys via the course website and supplied their responses online.

\section{Modules}

The online statistics modules were created using Macromedia's Flash 4.0. The modules were designed to serve as introductory platforms for statistics principles. The modules were available for viewing on the course web site. Students were required to log onto the course web site and view these modules before they came into class. After viewing the modules, students filled out online quizzes and surveys. Four percent of a student's final grade was based on completion of the module assignment. For each computerized module, the student received half of the assignment's credit for scoring a 50\% or better on the associated quiz and half of the credit for taking the module's survey. The instructor could then tailor class lectures to address student deficiencies based on performance on the computerized modules. Because the introduction phase of statistic topics was moved out of class time, the instructor had more in-class time to explore topics with 
more depth and cover a wider range of material. The five modules are briefly described below.

\section{Descriptive Statistics}

The descriptive statistics module sought to introduce the basic principles of central tendency and variability. The central tendency topics included mean, median, and mode. The variability topics included range, variance, and standard deviation.

For each topic, a formal definition and equation was presented. Then, a working example was presented (Figure 1). The example concerned elephants' weights (in tons). Each topic used this same elephant example in order to maintain continuity. For each respective scene, the mean, median, and mode of the elephants' weights were calculated. The same procedure was done for the variance, standard deviation, and range.

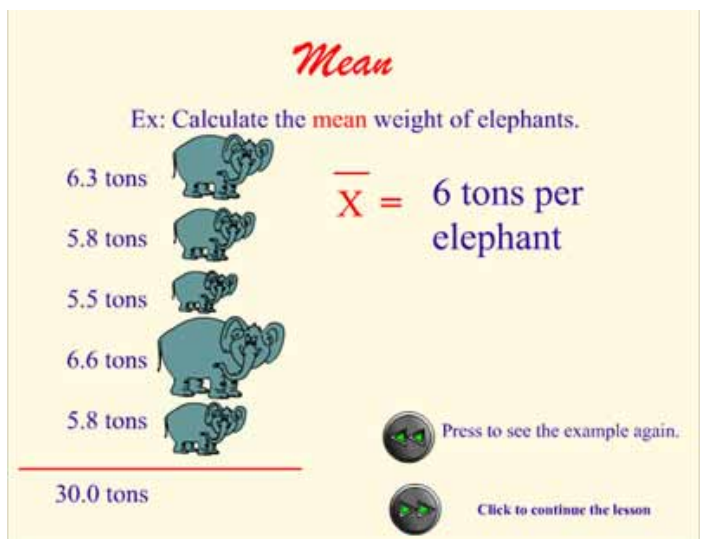

Figure 1: Descriptive Statistics Module

\section{Sample Spaces}

The sample spaces module explained event relationships. It also explained that Venn diagrams show the relationship among the various events inside a sample space. The sample events covered in this module were union, intersection, complement, and mutual exclusivity (Figure 2). The user clicked a button next to each event type to see a definition and a pictorial example of the Venn diagram for the chosen event. 


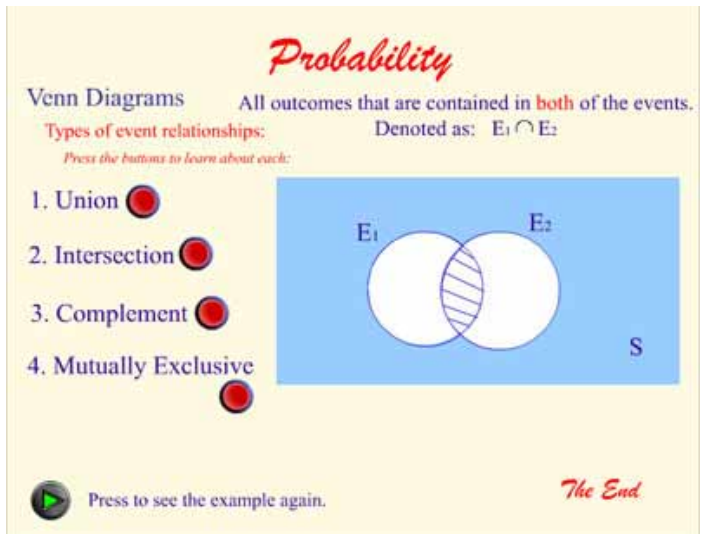

Figure 2: Sample Spaces Module

\section{Probability}

The probability module made some preliminary comments regarding probability and its connection with inferential statistics. Various aspects of probability were defined and then demonstrated using an example (experiment, sample spaces, and events).

Permutation was also covered. The permutation definition was given and an example for finding possible arrangements of colored balls (red, blue, and green) was presented. When the user clicked each combination possibility, the balls would rearrange in that particular order.

The module also included conditional probability. Again, formal definitions were given and the same gear integrity example was used (Figure 3). The example called for finding the probability that a gear has chipping given that wearing is present. Each step of the calculation is illustrated.

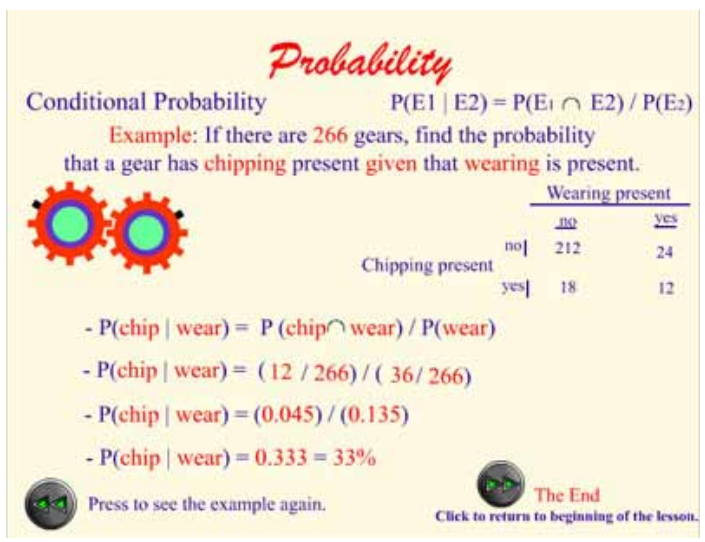

Figure 3: Probability Module 


\section{Central Limit Theorem}

The central limit theorem module provided the formal statement of the central limit theorem and used the example of dice rolling ${ }^{11}$ to show how a distribution takes on the characteristics of a normal distribution (Figure 4). It then explained the dice rolling example and how it relates to the central limit theorem. The module then contained successive scenes in which the user had to "roll the dice". The module explained the calculation of the average score. In each successive scene, there was an increasing number of dice used. The user would click a button and the dice would roll across the screen and show a bar graph of the distribution of average scores.

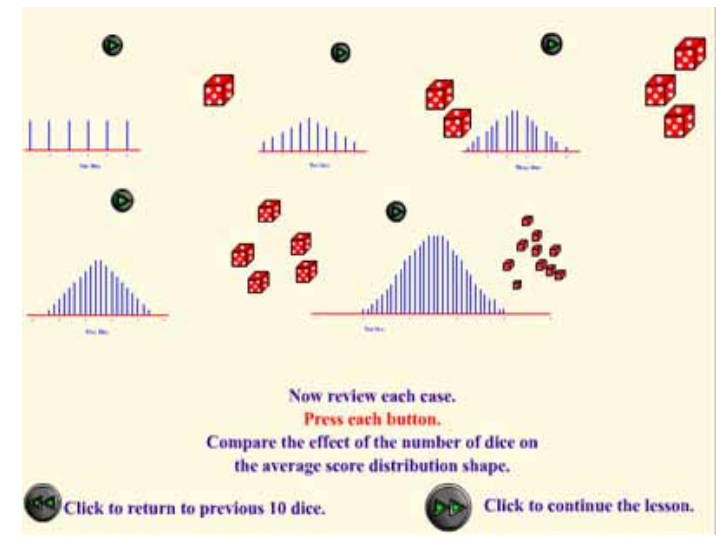

Figure 4: Central Limit Theorem Module

Two-Sample Hypothesis Testing

The two-sample hypothesis-testing module ${ }^{5}$ used both animation and narration to explain this concept (Figure 5). The example given in the module tested to see if the average diameter of oranges was larger than apples. The null hypothesis stated that the average diameter of apples and oranges were the same. The alternative hypothesis stated that the average diameter of oranges were larger than apples. The example intended to reject the null hypothesis. The assumptions that the population of apples and oranges were independent and normally distributed were made. The module used normal distribution graphs to illustrate rejection regions. A moving rejection criteria line animated how reducing the probability of a Type I error $(\alpha)$ increases the probability of a Type II error $(\beta)$, and vice-versa. The case with large sample $(n>30)$ and known variances was presented. The module demonstrated how to calculate the Z-test statistic and how to determine whether or not to reject this hypothesis. 


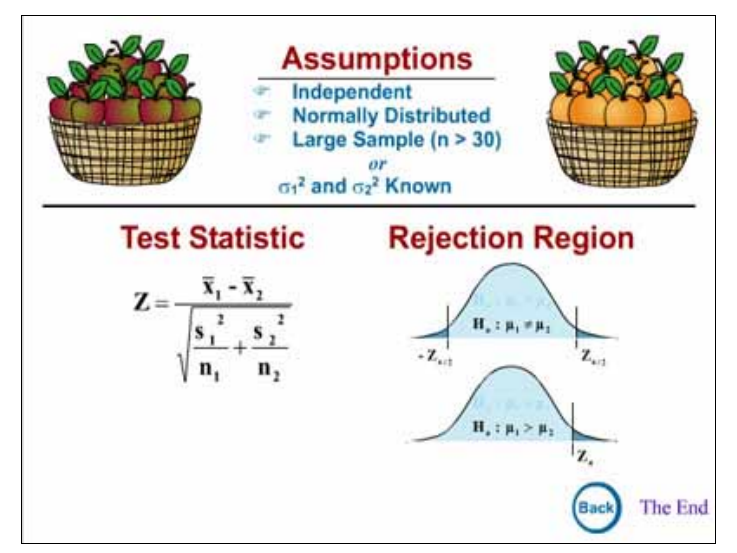

Figure 5: Two-Sample Hypothesis Testing

VII. Module Procedure

An in-depth analysis of a module is the best approach to describe the general procedure and characteristics of all the modules. The descriptive statistics module will be described scene by scene.

The descriptive statistics module is designed to introduce the students to descriptive statistics such as mean, median, mode, and variability. The introductory scene (Figure 6) reveals the topics included in the module and explains that the topics will be demonstrated with an example. The example will be a descriptive statistics analysis of the weight of elephants. The viewer clicks the forward button to advance linearly through the module. A table of topics is also present. The viewer can select a particular topic and directly proceed to that particular scene. This table is convenient for viewers who wish to review a particular topic instead of all the topics. And, as with every scene, a replay button allows the viewer to review the current scene.

\section{Deseriptive Statistics}

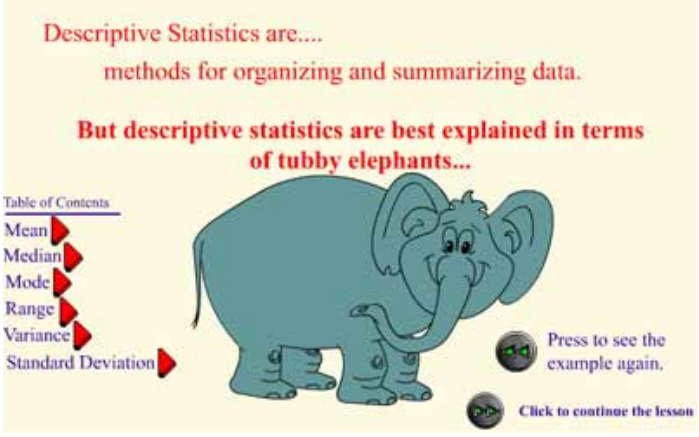

Figure 6: Initial Scene 
The module then proceeds to the next scene concerning statistical mean. This scene (Figure 7) demonstrates the calculation method for statistical mean. First, the mathematical equation for mean is presented. The module then demonstrates the calculation. The module computes the mean weight (measured in tons) of five elephants. This procedure is animated for the viewer. The viewer sees that five elephants with a total mass of 30 tons have a mean weight of 6 tons.

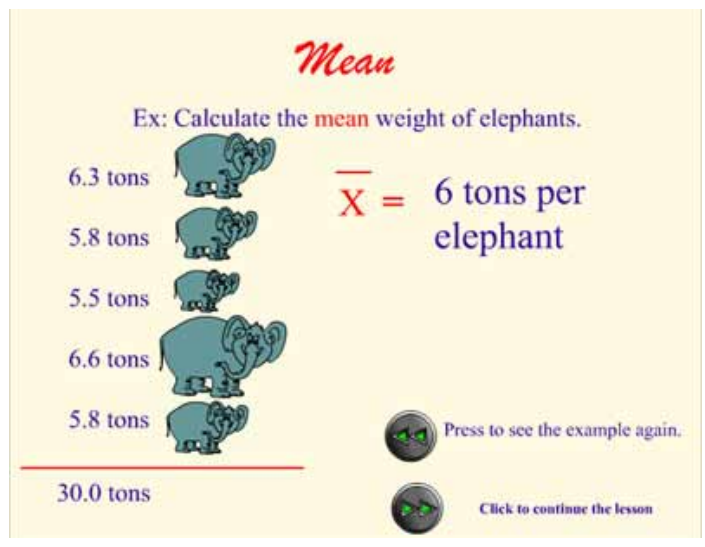

Figure 7: Mean Demonstration

Median is covered in the next scene. The scene (Figure 8) first gives the viewer the formal definition of median. The scene then demonstrates median in two steps. The first step is to rank the data in ascending order. The elephants re-arrange themselves in increasing order according to weight. An arrow points out the middle observation of the ordered data (5.8 tons).

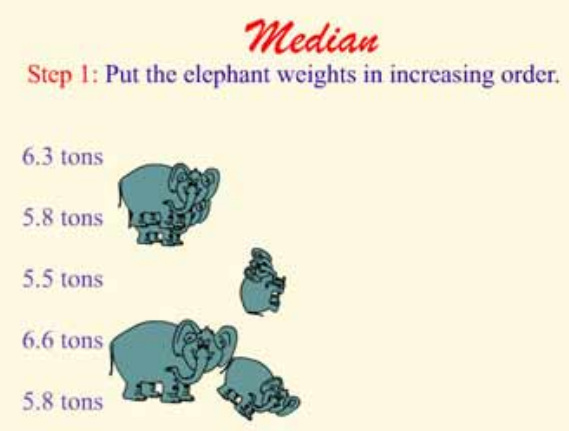

Figure 8: Moving Elephants into Rank Order

In the next scene, the definition for mode is shown first. The mode scene (Figure 9) also explains the difference between unimodal and bimodal. The scene then finds the mode of the elephants' weights by pointing out that two of the five elephants have the same mass (5.8 tons). Therefore, 5.8 tons is the mode of the data. 


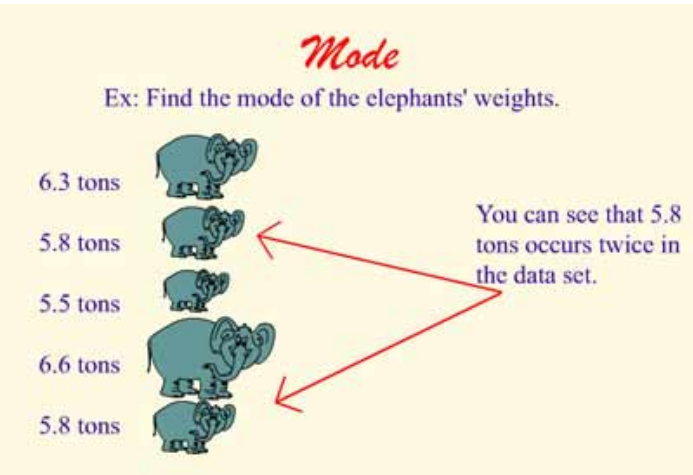

Figure 9: Calculating the Mode

Variability is covered in the next three scenes. Range is the first variability topic presented (Figure $10)$. Range is the difference between the largest and smallest sample observations. The module selects the smallest (5.5 tons) and largest (6.6 tons) observations and subtracts the former from the latter. The resulting value is 1.1 tons.

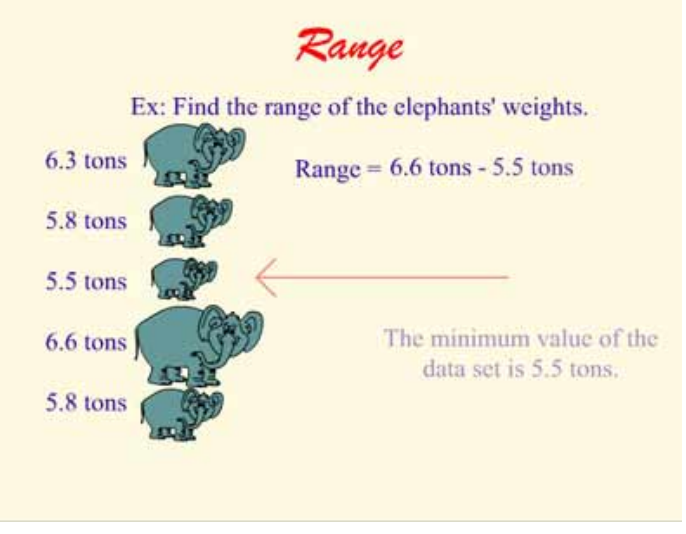

Figure 10: Finding the Range

Variance is the next scene (Figure 11) of the descriptive statistics module. The variance equation is unveiled and the module calculates the variance for the elephants. Recalling that the mean is 6 tons per elephant, the squared differences of the mean minus the observation is calculated and the results are summed. The sum is then divided by $n-1$ observations. The variance is shown to be 0.195 square-tons. 


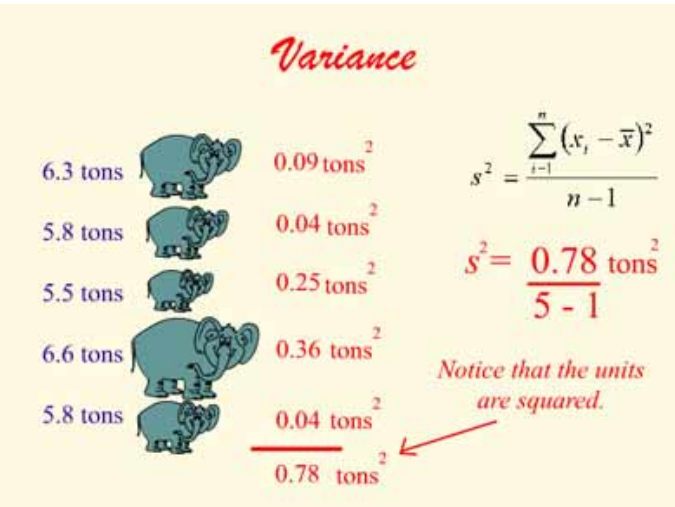

Figure 11: Solving for Variance

Finally, standard deviation is presented. The standard deviation scene (Figure 12) explains that standard deviation is the positive square root of the variance. Recalling from the previous scene that the variance 0.195 square-tons, the square root of the variance is found to be 0.442 tons.

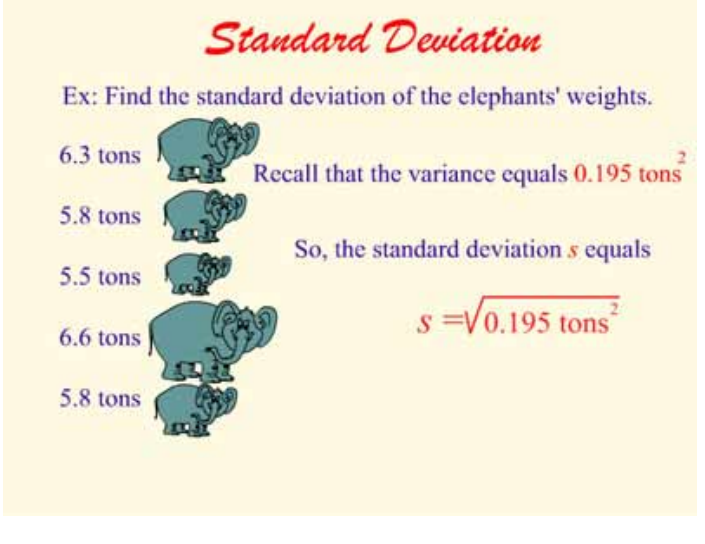

Figure 12: Solving for Standard Deviation

\section{Module Quizzes}

Similar to every module, viewers of the descriptive statistics module are required to take an associated quiz. The quiz measures knowledge after viewing the module. Instructors use the quiz results to find areas of strength and weakness.

The quiz questions for the descriptive statistics module are shown in Table 2. Answers are indicated with a check mark. 
Table 2: Descriptive Statistics Module Quiz

\begin{tabular}{|c|c|c|}
\hline & Question & Possible Responses \\
\hline 1 & $\begin{array}{l}\text { The following are the numbers of twists that were } \\
\text { required to break } 12 \text { forged alloy bars. } \\
33,24,39,48,26,35,38,54,23,34,29,37 \\
\text { Find the mean. }\end{array}$ & $\begin{array}{l}30 \text { twists } \\
35 \text { twists } \sqrt{ } \\
29 \text { twists } \\
33 \text { twists }\end{array}$ \\
\hline 2 & $\begin{array}{l}\text { The following are the numbers of twists that were } \\
\text { required to break } 12 \text { forged alloy bars. } \\
33,24,39,48,26,35,38,54,23,34,29,37 \\
\text { Find the median. }\end{array}$ & $\begin{array}{l}34.5 \text { twists } \sqrt{ } \\
34 \text { twists } \\
33.5 \text { twists } \\
35 \text { twists }\end{array}$ \\
\hline 3 & $\begin{array}{l}\text { If the mean annual salary paid to the chief executives } \\
\text { of three engineering firms is } \$ 125,000 \text {, could one of } \\
\text { them receive } \$ 400,000 \text { ? }\end{array}$ & $\begin{array}{l}\text { True } \\
\text { False } \sqrt{ }\end{array}$ \\
\hline 4 & $\begin{array}{l}\text { The recent temperatures in Phoenix, Arizona were } \\
\text { 104, 100, 105, 99, and } 69 \text { degrees Fahrenheit. Find } \\
\text { the variance. }\end{array}$ & $\begin{array}{l}255 \text { degrees }^{2} \\
221.7 \text { degrees }^{2} \\
224.3 \text { degrees }^{2} V \\
200.8 \text { degrees }^{2}\end{array}$ \\
\hline 5 & $\begin{array}{l}\text { The recent temperatures in Phoenix, Arizona were } \\
104,100,105,99 \text {, and } 69 \text { degrees Fahrenheit. Find } \\
\text { the standard deviation. }\end{array}$ & $\begin{array}{l}20 \text { degrees } \\
200 \text { degrees } \\
24 \text { degrees } \\
15 \text { degrees } \sqrt{ }\end{array}$ \\
\hline 6 & $\begin{array}{l}\text { Considering the recent temperatures in Phoenix, } \\
\text { Arizona. If someone mentioned that the daily climate } \\
\text { in Phoenix was a pleasant } 95.4 \text { degrees Fahrenheit, is } \\
\text { this deceptive? }\end{array}$ & $\begin{array}{l}\text { Yes } \sqrt{ } \\
\text { No }\end{array}$ \\
\hline
\end{tabular}

The student results for the descriptive statistics quiz can be seen in Table 3 .

Table 3: Student Results to the Descriptive Module Quiz

\begin{tabular}{|c|l|}
\hline Question & \multicolumn{1}{|c|}{ Responses } \\
\hline 1 & 30 twists \\
& 35 twists $\sqrt{ } 100 \%$ \\
& 29 twists \\
& 33 twists \\
\hline 2 & 34.5 twists $\sqrt{ } 100 \%$ \\
& 34 twists \\
& 33.5 twists \\
& 35 twists \\
\hline 3 & True $22 \%$ \\
& False $\sqrt{ } 78 \%$ \\
\hline
\end{tabular}

Proceedings of the 2001 American Society for Engineering Education Annual Conference \& Exposition Copyright (O) 2001, American Society for Engineering Education 


\begin{tabular}{|c|c|}
\hline 4 & $\begin{array}{l}255 \text { degrees squared } \\
221.7 \text { degrees squared } \\
224.3 \text { degrees squared } \sqrt{ } 98 \% \\
200.8 \text { degrees squared } \quad 2 \%\end{array}$ \\
\hline 5 & $\begin{array}{l}20 \text { degrees } \\
200 \text { degrees } \\
24 \text { degrees } \quad 2 \% \\
15 \text { degrees } \sqrt{ } 98 \%\end{array}$ \\
\hline 6 & $\begin{array}{l}\text { Yes } \sqrt{ } 63 \% \\
\text { No } \quad 37 \%\end{array}$ \\
\hline
\end{tabular}

As seen in Table 3, the students mastered questions 1, 2, 4, and 5. These questions are simple calculation questions. The questions require that the student apply the appropriate statistical equation and solve it. The results indicate that the students successfully choose the appropriate equation and correctly solved the problem.

Students did not have the same level of success with questions 3 and 6 . These questions were not straightforward calculation questions. These questions' nature was a higher level of learning. The questions pushed the student to use their newfound knowledge about descriptive statistics in a more analytical manner.

Question 3 asked the students if the mean annual salary paid to the chief executives of three engineering firms is $\$ 125,000$, could one of them receive $\$ 400,000$ ? The answer is false. By using the equation for statistical mean, there is no possible way that the mean salary can be $\$ 125,000$ if one of the three executives' salary is $\$ 400,000$. Seventy-nine percent of the students correctly answered false. This is a high percentage, but not quite as high as $98 \%$ or $100 \%$.

Question 6 asked the students if someone mentioned that the daily climate in Phoenix was a pleasant 95.4 degrees Fahrenheit, is this deceptive? The students examined the recent temperatures in Phoenix, Arizona given in question 5. The temperatures were 104, 100, 105, 99, and 69 degrees Fahrenheit. The student could easily confer that the mean temperature in Phoenix was 95.4 degrees Fahrenheit based on the given data. The validity of this mean temperature is what was brought into question. The modules did not explicitly address the issue of statistical deception. The student had to reason that this mean value of 95.4 degrees Fahrenheit was deceptive based on the fact that one of the temperature observations was 69 degrees Fahrenheit. This unusually low temperature value skewed the mean temperature. Without this low value, the mean temperature is 102 degrees Fahrenheit. Only $63 \%$ of the quiz takers noticed this happenstance.

Based on these results, it was concluded that the students are able to perform low learning level tasks such as knowledge and application. However, students could not perform as well at the higher levels of cognition. 


\section{Descriptive Statistics Survey}

Surveys were made available for each module. These surveys are essential to gauging student receptiveness to the modules. The surveys also serve as a means to gain insight about possible module improvement. The students were required to fill out the survey in order to receive half of the credit for their computer module grade. The survey asked about the module's effectiveness and its organization (Table 4).

\section{Table 4: Descriptive Module Survey}

\begin{tabular}{|c|c|c|}
\hline & Question & Example Response \\
\hline 1 & $\begin{array}{l}\text { Did this module aide you in learning } \\
\text { about central tendency? }\end{array}$ & $\begin{array}{l}\text { Yes, this module helped me refresh my } \\
\text { memory about central tendencies. }\end{array}$ \\
\hline 2 & $\begin{array}{l}\text { Did this module aide you in learning } \\
\text { about variability (range, variance, } \\
\text { standard deviation)? }\end{array}$ & $\begin{array}{l}\text { Yes, it was a good review about material } \\
\text { that I had learned many years ago. }\end{array}$ \\
\hline 3 & Was the module organized well? & $\begin{array}{l}\text { Yes, but it was too slow in places and too } \\
\text { fast in others }\end{array}$ \\
\hline 4 & $\begin{array}{l}\text { What is your attitude about this module } \\
\text { on descriptive statistics? }\end{array}$ & $\begin{array}{l}\text { My attitude, overall, about this module is } \\
\text { very positive. }\end{array}$ \\
\hline 5 & $\begin{array}{l}\text { Did you consult your textbook before } \\
\text { viewing the modules? Yes or No }\end{array}$ & Yes \\
\hline 6 & $\begin{array}{l}\text { Did you consult your textbook while } \\
\text { viewing the modules? Yes or No }\end{array}$ & No \\
\hline 7 & $\begin{array}{l}\text { Did you consult your textbook while } \\
\text { taking the quiz? Yes or No }\end{array}$ & Yes \\
\hline
\end{tabular}

The qualitative answers obtained were used for improvement of future versions of the module. For example, a survey response for Question 3 (Table 4) stated, "Yes, but it was too slow in places and too fast in others." This response beckoned consideration among the authors to add pacing buttons to the modules. These buttons would be placed after each passage of text or mathematical equation. The student would click the button to continue the module. This allows for students to be in control of information presentation rate, thus better assuring that the student retains the information presented.

\section{Cognitive Results and Analysis}

Grades provide insight to any cognitive performance change due to the presence of the statistics modules. Below are tables and discussion concerning class grades. It was discovered that the grade percentage for each semester was remarkably similar. A two-sample hypothesis test on percentage was performed $(\alpha=0.05)$ for each of the various comparisons. As expected, there was found to be no significant difference between any of the semester's grade percentages except for one 
homework assignment (Probability, Table 8). P-values were calculated for each hypothesis test.

First, the overall class grade average was considered. It was found that the overall class percentage for each semester was almost identical (Table 5).

\section{Table 5: Overall Class Grade}

\begin{tabular}{|c|c|c|c|c|}
\hline & $\begin{array}{c}\text { Spring } \\
\text { (No Module) }\end{array}$ & $\begin{array}{c}\text { Fall } \\
\text { (Module) }\end{array}$ & Difference & P-value \\
\hline Class Grade Average & 0.85 & 0.84 & 0.01 & 0.88 \\
\hline Class Grade Std. Dev. & 0.073 & 0.069 & 0.004 & 0.73 \\
\hline
\end{tabular}

Next under consideration were the two class projects: the mid-term project and the final project. The midterm project for the spring semester was a probability problem involving the design of a game utilizing a catapult device. The fall semester mid-term project was a probability problem involving the failure rate of a computer component. Both of these projects were concerning normal distributions. For the final project, both semesters' students were assigned a poster session project. The students were required to perform a two-sample hypothesis test from some collected data and present their finding in the format of a poster presentation. The scoring percentages for each project were slightly higher for the spring semester (Table 6 and Table 7). Again, these differences were not significant.

Table 6: Midterm Project Grade

\begin{tabular}{|c|c|c|c|c|c|}
\hline & $\frac{\text { Spring }}{(\text { No Module) }}$ & Fall & Difference & P-value \\
Class Midterm Project Average & 0.92 & 0.88 & 0.04 & 0.53 \\
\hline Class Midterm Project Std. Dev. & 0.11 & 0.05 & 0.06 & 0.002 \\
\hline
\end{tabular}

Table 7: Final Project Grade

\begin{tabular}{|c|c|c|c|c|}
\hline & $\begin{array}{c}\text { Spring } \\
\text { (No Module) }\end{array}$ & $\begin{array}{c}\text { Fall } \\
\text { (Module) }\end{array}$ & Difference & P-value \\
\cline { 1 - 3 } Class Final Project Average & 0.95 & 0.93 & 0.02 & 0.70 \\
\hline Class Final Project Std. Dev. & 0.05 & 0.07 & -0.02 & 0.03 \\
\hline
\end{tabular}

Also under review were homework assignments that dealt specifically with two statistics modules (Probability and Hypothesis Testing). It was desired to learn if the students in the fall semester had any additional benefits over the students in the spring semester when it came to the topics covered in the statistic modules. The grades indicate that this was not the case. There was a small decrease for the first homework set (Table 8). For the second homework set, there was no change in scoring average (Table 9). 
Table 8: Probability Homework Grade

\begin{tabular}{|c|c|c|c|c|}
\hline & $\begin{array}{c}\text { Spring } \\
\text { (No Module) }\end{array}$ & $\begin{array}{c}\text { Fall } \\
\text { (Module) }\end{array}$ & Difference & P-value \\
\hline Probability Homework Average & 0.94 & 0.80 & 0.14 & 0.07 \\
\hline Probability Homework Std. Dev. & 0.09 & 0.32 & 0.23 & 0.00 \\
\hline
\end{tabular}

Table 9: Hypothesis Testing Homework Grade

\begin{tabular}{|c|c|c|c|c|}
\hline & $\begin{array}{c}\text { Spring } \\
\text { (No Module) }\end{array}$ & $\begin{array}{c}\text { Fall } \\
\text { (Module) }\end{array}$ & Difference & P-value \\
\hline Hypo. Test HW Average & 0.73 & 0.73 & 0.00 & 0.98 \\
\hline Hypo. Test HW Std. Dev. & 0.35 & 0.29 & 0.06 & 0.23 \\
\hline
\end{tabular}

\section{Attitude Survey}

As stated previously, this research also took advantage of the attitudinal aspect of course reception. Research has tended to show that student attitude is related to student performance in the course ${ }^{12,}$ ${ }^{14}$. It is hoped that a positive attitude can make an impact upon a student's reception of the material. The attitude survey was used to detect any change in attitude between the two semesters and any change within each semester.

Students were given pre and post semester surveys. The SATS survey is sub-divided into four sections: affect, cognitive competence, value, and difficulty. The question types were randomly arranged throughout the survey. Affect covers general feelings concerning statistics (such as frustration, stress, and enjoyment). Cognitive competence deals with attitudes about intellectual knowledge and skills when applied to statistics (e.g. "I can learn statistics"). Value is about the usefulness, relevance, and worth of statistics in personal and professional life (e.g. "Statistics will make me more employable"). Difficulty concerns the overall difficulty of the subject statistics (e.g. "Statistics is a complicated subject").

Questions were asked in both positive and negative fashion. For instance, a positive question was "I like statistics". A negative question was "I am scared by statistics". Students respond on an agreement range from 1 - 7, where "1" equates to "Strongly Disagree", "4" equates to "Neither Disagree nor Agree", and "7" equates to "Strongly Agree".

Scoring was conducted by first reversing the responses to the negative questions. For example, a response of "5" for the question "I am scared by statistics" would change to a response of "2". Therefore, all questions are positive. Scores are summed and averaged for each subscale. Thus, a higher score corresponds to a more positive attitude. 
Student attitude analysis between the Spring and Fall semesters found very similar results. A hypothesis test on two means with unknown population variance was performed (t-test with $\alpha=$ 0.05). The null hypothesis was no difference in mean score. Both the equal and unequal variance cases were used to compare. It was found that both yielded almost exact results. Thus, the unknown and equal population variance scenario was used.

As seen in Tables 10 thru 13, there was almost no difference between the Spring and Fall semesters. None of the differences were of statistical significance except the value component for the post survey. The post-survey value for the Fall semester decreased from that of the Spring survey. However, it should be noted that the average score for value (5.23 and 4.70 for Spring and Fall, respectively) was the second highest of the components. Overall, cognitive competence was the best received, while difficulty was least received.

Table 10: Affect Between Semesters

\begin{tabular}{|c|c|c|c|c|}
\hline & $\begin{array}{c}\text { Spring } \\
\text { (No Module) }\end{array}$ & $\begin{array}{c}\text { Fall } \\
\text { (Module) }\end{array}$ & Difference & P-value \\
\hline Pre-semester Survey & 4.46 & 4.56 & 0.10 & 0.48 \\
\hline Post-semester Survey & 4.62 & 4.37 & -0.25 & 0.12 \\
\hline
\end{tabular}

Table 11: Cognitive Competence Between Semesters

\begin{tabular}{|c|c|c|c|c|}
\hline & $\begin{array}{c}\text { Spring } \\
\text { (No Module) }\end{array}$ & $\begin{array}{c}\text { Fall } \\
\text { (Module) }\end{array}$ & Difference & \multirow{2}{*}{ P-value } \\
\hline \hline Pre-semester Survey & 5.15 & 5.21 & 0.06 & 0.70 \\
\hline Post-semester Survey & 5.12 & 5.04 & -0.08 & 0.61 \\
\hline
\end{tabular}

Table 12: Value Between Semesters

\begin{tabular}{|c|c|c|c|c|}
\hline & $\begin{array}{c}\text { Spring } \\
\text { (No Module) }\end{array}$ & $\begin{array}{c}\text { Fall } \\
\text { (Module) }\end{array}$ & Difference & P-value \\
\hline Pre-semester Survey & 5.20 & 5.19 & -0.01 & 0.94 \\
\hline Post-semester Survey & 5.23 & 4.70 & -0.53 & 0.00001 \\
\hline
\end{tabular}

Table 13: Difficulty Between Semesters

\begin{tabular}{|c|c|c|c|c|}
\hline & $\begin{array}{c}\text { Spring } \\
\text { (No Module) }\end{array}$ & $\begin{array}{c}\text { Fall } \\
\text { (Module) }\end{array}$ & Difference & P-value \\
\hline \hline Pre-semester Survey & 3.70 & 3.60 & -0.10 & 0.39 \\
\hline Post-semester Survey & 3.82 & 3.71 & -0.11 & 0.40 \\
\hline
\end{tabular}

Student attitude analysis within each semester also found very similar results. A paired-t 
hypothesis test on two means with unknown population variance was performed $(\alpha=0.05)$. The null hypothesis was no difference in mean score.

Within semester comparison proved almost no difference either (See Tables 14 thru 17). Neither the traditional teaching approach nor the computer module teaching approach was able to significantly improve attitude from the beginning to the end of the semester. Only the value component of attitude in the Fall semester was significantly different. The student attitude toward value decreased.

Table 14: Affect Within Semester

\begin{tabular}{|c|c|c|c|c|}
\hline & Pre & Post & Difference & P-value \\
\hline Spring (No Module) & 4.46 & 4.62 & 0.18 & 0.15 \\
\hline Fall (Module) & 4.56 & 4.37 & -0.19 & 0.13 \\
\hline
\end{tabular}

Table 15: Cognitive Competence Within Semester

\begin{tabular}{|c|c|c|c|c|}
\hline & Pre & Post & Difference & P-value \\
\hline Spring (No Module) & 5.15 & 5.12 & -0.03 & 0.72 \\
\hline Fall (Module) & 5.21 & 5.04 & -0.17 & 0.21 \\
\hline
\end{tabular}

Table 16: Value Within Semester

\begin{tabular}{|c|c|c|c|c|}
\hline & Pre & Post & Difference & P-value \\
\hline Spring (No Module) & 5.20 & 5.23 & 0.03 & 0.70 \\
\hline Fall (Module) & 5.19 & 4.70 & -0.49 & 0.000005 \\
\hline
\end{tabular}

Table 17: Difficulty Within Semester

\begin{tabular}{|c|c|c|c|c|}
\hline & Pre & Post & Difference & P-value \\
\hline Spring (No Module) & 3.70 & 3.82 & 0.12 & 0.20 \\
\hline Fall (Module) & 3.60 & 3.71 & 0.11 & 0.24 \\
\hline
\end{tabular}

The modules did not lead to an increased positive attitude as hoped. Overall, the attitudes between and within semesters were almost unchanged. Even though the Value component decrease, it still received an above neutral ranking. All components received neutral to slightly positive scores.

\section{Discussion and Conclusion}

The goal of this research was to study the effect that computerized statistics modules had on students in an engineering statistics course. Effect was measured on two levels: cognitive and affective. Cognitive performance was measured via grades earned on homework, tests, and 
projects. Affective performance was measured via a survey of their attitudes toward this statistics course and the topic of statistics in general.

There were three hypotheses: significant positive improvement in academic performance between semesters, significant positive improvement in attitude between semesters, and significant positive improvement within each semester. Each hypothesis did not materialize.

There was found to be no statistical difference in cognitive performance between the semester without statistics modules and the semester with statistics modules. The overall class percentage for each semester was almost identical (85\% vs. 84\%). Further, there were insignificant changes in grades received for class projects and homework assignments related to the modules.

Analysis of the affective performance also revealed no statistical difference between the semester without computer modules and the semester with computer modules. Further, there was no within semester attitude change. Only one of the four components (value) for the Fall semester saw some decreased change. Overall, the computer modules had no distinct impact on attitude.

Module usage in course curriculum is still hopeful. There is great potential for using modules because they are very accessible and asynchronous. Better integration into the course, as well as better technical support, would probably improve module effectiveness. The modules could also benefit from being designed with more user-interactivity (as opposed to passively viewing).

Bibliography

1. Azemi, Asad. Developing an Active Learning Environment with Courseware Approach. Frontiers in Education, Session S1D, p.p. 1179-1184 (1997).

2. Besterfield-Sacre, M.E., Atman, C.J., and Shuman, L.J. Characteristics of Freshman Engineering Students: Models for Determining Student Attrition and Success in Engineering. The Journal of Engineering Education, Vol. 86, p.p. 139-149 (1997).

3. Besterfield-Sacre, M.E., Atman, C.J., and Shuman, L.J. Engineering Attitudes Assessment. The Journal of Engineering Education, Vol. 87, p.p. 133-141 (1998).

4. Bloom, Benjamin S. Taxonomy of Educational Objectives, The Classification of Educational Goals; Handbook I: Cognitive Domain. David McKay Company, Inc., New York (1969).

5. Fry, Tamy. Two-sample module created in 1999.

6. Goodson, Carole E. and Susan L. Miertschin and Sue Schroeder and Patrick Daniel. Experiences with Video Enhanced Collaborative Learning. The American Society of Engineering Education, Session 1649 (1999).

7. Hailey, Christie E. and David E. Hailey, Jr. Evaluation of Student Preferences and Learning Outcomes of Computer Based Teaching for a Manufacturing Processes Laboratory. The American Society of Engineering Education, Session 2520 (1998).

8. Hawley, John A. and Billy L. Crynes. Stimulating Development of Technology Based Teaching/Learning Modules Through a Technical Elective. Frontiers in Education, Session S3E, p.p. 1399-1401 (1997).

9. Keyvan, Shahla and Xiaolong Song and Rodney Pickard. Computer-based Teaching and Assessment in Topics on Basic Physics. The American Society of Engineering Education, Session 3280 (1998).

10. McCartney, Robert and Bob Weiner and Karl R. Wurst. Delivering a lab course in a web-based learning environment. Frontiers in Education, Session F3B, p.p. 849-855 (1997).

11. Montgomery, D. C. and G. C. Runger Applied Statistics and Probability for Engineers, Second Edition. John Wiley \& Sons Inc., New York, NY (1999).

Proceedings of the 2001 American Society for Engineering Education Annual Conference \& Exposition Copyright (C) 2001, American Society for Engineering Education 
12. Rhoads, Teri Reed and Norma Faris Hubele. Student Attitudes Toward Statistics Before and After a Computerintegrated Introductory Statistics Course. IEEE Transactions in Education, Vol. 43, No. 2, p.p. 182-187 (2000).

13. Rhoads, T.R., Zimmer, L., Lewis, S., \& Hubele, N.F. Taking Students to the Top - Evaluation. American Society of Engineering Education Pacific Southwest Section 1997 Conference, San Luis Obispo, CA, March 14-15 (1997).

14. Roiter, K. and Petocz, P. Introductory Statistics Courses - A new Way of Thinking. Journal of Statistics Education. Vol. 4, No. 2 (1996).

15. Schau, C., Stevens, J., Dauphinee, T.L., \& Del Vecchio, A. The Development and validation of the Survey of Attitudes Toward Statistics. Educational and Psychological Measurement. Vol. 55, 868-875 (1995).

16. Taylor, C. and D.B. Growler. Academic Uses of FrontPage 97. The Technology Source (1998).

17. Toogood, Roger and Bill Lipsett and Shelley Lorimer and Terry Hrudey and Art Peterson and Stanley Varnhagen. Computer Based Learning for Engineering Mechanics: "If we build it, will they come?" The American Society of Engineering Education, Session 3666 (1998).

Barry Mauldin

Barry Mauldin is currently a graduate student at the University of Oklahoma. He received his B.S. degree in Industrial Engineering from the University of Oklahoma in 1999. His interests reside in multimedia integration with educational instruction. In addition to research, Barry has served the University of Oklahoma's School of Industrial Engineering as a founding member of the Multimedia Technology Group and as a teaching assistant for Engineering Statistics course.

Teri Reed Rhoads

Teri Reed Rhoads is an Assistant Professor of Industrial Engineering at the University of Oklahoma. She also serves as the Assessment Advisor to the College of Engineering. Dr. Rhoads is actively involved in research with industry as well as with the National Science Foundation. Her areas of interest are engineering education and assessment as well as quality engineering. Dr. Rhoads received a B.S. degree in Petroleum Engineering from the University of Oklahoma in 1985, a Masters in Business Administration from the University of Texas of the Permian Basin in 1992, and a Ph.D. in Industrial Engineering from Arizona State University in 1999.

Proceedings of the 2001 American Society for Engineering Education Annual Conference \& Exposition

Copyright (C) 2001, American Society for Engineering Education 